\title{
Bachelard: libido, razón, conocimiento y espíritu científico. Hacia una comprensión alternativa de la noción de obstáculo epistemológico
}

\author{
Bachelard: Libido, Reason, Knowledge and Scientific \\ Spirit: Towards an Alternative Understanding \\ of the Notion of Epistemological Obstacle
}

\author{
Gerardo Andrés Perafán Echeverri ${ }^{1}$
}

\section{Resumen}

En el texto se aborda un desarrollo alternativo de las categorías bachelardianas de obstáculo y ruptura epistemológica, a partir del establecimiento de algunas relaciones teóricas posibles entre Platón, Freud, Jung y Bachelard. En general, se plantea que tanto para Bachelard como para Platón el devenir del espíritu científico se explica a partir del inconsciente individual y colectivo, con lo cual la razón aparece como una función de este último. Por otro lado, se señala cómo el desprendimiento, ruptura o mutación va de la proyección de los primeros arquetipos en las "cosas", a la función de organización o razón polémica, en lo que puede considerarse como un tipo de proyección particular, quizá más elaborada, que Bachelard llamará realización.

\section{Palabras clave}

Obstáculo epistemológico, ruptura epistemológica, razón como función del inconsciente.

\section{Abstract}

This text deals with an alternative development of the Bachelardian categories of epistemological obstacle and break, from the establishment of some possible theoretical relationships between Plato, Freud, Jung y Bachelard. In general, it proposes that for both Bachelard and Plato, the evolution of the scientific spirit is explained from the individual and collective unconscious, with which reason appears as a function of the latter. On the other hand, it is noted how the detachment, break or mutation comes from the projection of the first archetypes in the "things", to the function of organisation or controversial reason, in what can be considered a type of particular projection, which perhaps is more elaborate than what Bachelard would call fulfillment.

Key words

Epistemological obstacle, epistemological break, reason as the unconscious function.

Artículo recibido el 4 de agosto de 2014 y aprobado el 7 de abril de 2015

1 Universidad Pedagógica Nacional, Bogotá, Colombia. Correo electrónico: anperafan@yahoo.com 
No existen razones para pensar que la imagen científica del Universo natural haya influido inmediatamente en las diversas relaciones de los hombres con la naturaleza, por ejemplo en la del artista moderno. Más aceptable parece la idea de que las alteraciones en los fundamentos de la moderna ciencia de la Naturaleza son indicios de alteraciones hondas en las bases de nuestra existencia.

(Heisenberg, 1976, p. 7)

Por primera vez en el curso de la Historia el hombre no encuentra ante sí más que a sí mismo en el Universo.

(Heisenberg, 1976, p. 21)

\section{Introducción}

El título del presente artículo alude a una forma de comprender los procesos de producción del conocimiento humano en general, y del conocimiento científico en particular, los dos anudados de manera compleja, por no decir recursiva, al libido como estructura individual y colectiva. Por otra parte, se plantea el devenir del espíritu científico, a partir del inconsciente individual (estructura y dinámica de la fuerza pulsional endógena reprimida) y colectivo (arquetipos primitivos). Así mismo, se deja señalado el desprendimiento, ruptura o mutación que va de la proyección de los primeros arquetipos en las "cosas", a la función de organización o razón polémica, en lo que puede considerarse un tipo de proyección particular, quizá más elaborada, que Bachelard llamará realización. En otra perspectiva, se muestra que la dinámica del espíritu racional obedece a una forma específica de realización del amor, como un camino a la inmortalidad, o lo que es lo mismo: como acto creador constante que garantiza su ser en el devenir, en el cambio.

Esta tarea epistemológica tiene sus bases, por supuesto, en la obra de Bachelard, pero cobra sentido en relación con cuatro antecedentes fundamentales. En primer lugar, a nuestro juicio, la obra de Bachelard es incomprensible sin el Teeteto y el Banquete de Platón. Ciertamente, hay otras obras pertinentes como el Protágoras, el Parménides, el Menón y el Alcibíades; pero es en la relación TeetetoBanquete donde pueden encontrarse las huellas de una epistemología que estudia las bases psicológicas —además de lógicas y racionales-, del conocimiento y de la relación entre conocimiento y formación del espíritu. Una especie de solipsismo inevitable e inalienable parece dibujarse de nuevo ante nuestra reflexión, pero no con la esperanza de ser superado por la vía del interaccionismo entre las formas de individuación, sino como hecho que se impone dada la creación y la renovación perenne a la que tiende la fuerza generatriz universal que instituye también, $\mathrm{y}$ fundamentalmente, a lo humano y a sus criaturas.

La relación entre Rhome (amor, fuerza generatriz, daimon ${ }^{2}$ y pensamiento (alma, inteligencia), la cual no está exenta de tensiones, constituye un eje articulador para los aspectos relacionados con la episteme que se encuentran diseminados en las dos obras mencionadas. Aunque la primera aparentemente enfatice en psique y la segunda en eros, de lo que se trata en los dos diálogos es de la relación entre libido y conocimiento.

En segunda instancia, la obra de Jung constituye la fuente más próxima a la tesis de Bachelard, según la cual el árbol del saber humano se desprende del

2 Para referirse a esta fuerza generatriz Platón se pregunta: “¿Y qué poder tiene? [...] Interpreta y transmite a los dioses las cosas humanas y a los hombres las cosas divinas, las súplicas y los sacrificios de los unos y las órdenes y las recompensas a los sacrificios de los otros. Colocado entre unos y otros rellena el hueco, de manera que el Todo quede ligado consigo mismo. A través de él discurre el arte adivinatoria en su totalidad y el arte de los sacerdotes relativa a los sacrificios, a las iniciaciones, a los encantos, a la mantica toda y a la magia. La divinidad no se pone en contacto con el hombre (que es el alma según Alcibíades), sino que es a través de este género de seres por donde tiene lugar todo comercio y todo dialogo entre los dioses y los hombres, tanto durante la vigilia como durante el sueño" (Platón, Banquete, 201e). 
inconsciente, entendiendo este último como raíz o principio. En particular Psicología y alquimia y Psicología y simbólica del arquetipo son las obras que sirven de referencia en este escrito, donde se muestra con claridad la ruptura de Jung con el concepto de pulsión freudiano y la incorporación de la noción de arquetipos como constitutivos del inconsciente; de suerte que el árbol del saber humano (figura 1) aparece como proyección de los arquetipos primitivos a la materia. ${ }^{3}$ Esta forma específica de entender el inconsciente como conjunto de arquetipos y, en particular, la ruptura que marca con la noción "energética" freudiana, muestra de alguna manera la tensión en Bachelard, entre la libido y los arquetipos como formas de expresión de los obstáculos epistemológicos.

Figura 1. Árbol del saber

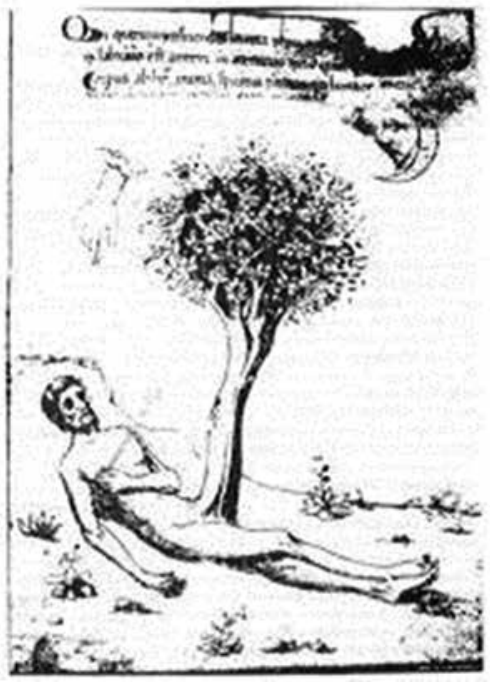

Fuente: Del códice Ashburn, 1166. En Miscellanea d'Alchimia, s. XV http://symbolos.com/libfg21.htm
3 Al respecto Jung afirma: “La verdadera naturaleza de la materia era desconocida para el alquimista, que sólo la conocía por alusiones. Al intentar investigarla, el alquimista proyectaba el inconsciente a la oscuridad de la materia para iluminarla. Y para explicar el misterio de la materia proyectaba otro misterio: precisamente su desconocido fondo psíquico en lo que tenía que explicar [...] Una proyección, en rigor de verdad, nunca se hace, sino que sencillamente ocurre. En la oscuridad de un hecho exterior encuentro, sin reconocerlo como tal, mi propio ser interior o psíquico [...] El alquimista vivía su proyección como una cualidad de la materia. Y lo que en realidad vivía era su propio inconsciente" (Jung, 2011, 268).
Por último, la obra de Freud, la cual parece impensable, como la de Bachelard, sin el Banquete de Platón. Particularmente, se toma como referencia Pulsiones y destinos de pulsión, La represión, Lo inconciente y Trabajos sobre metapsicología, conferencias todas de 1915. Aquí lo inconsciente se asume como una presunción teórica y práctica necesaria que se evidencia, según Freud, en "ocurrencias, cuyo origen desconocemos y con resultados de pensamiento cuyo trámite se nos oculta", pero que pueden ser conocidos o interpretados "si interpolamos los actos inconcientes inferidos" (Freud, 2008, p. 163). Aquí, la necesidad radica, entonces, en la ampliación del sentido consciente que ocurre merced al reconocimiento y al trabajo efectivo con los actos anímicos inconscientes; reconocimiento y "uso" que produce, adicionalmente, un impacto en la clínica.

Pero lo más relevante, para el objetivo presente, es asumir el reconocimiento que Freud hace del hecho de que

En cualquier momento dado, la consciencia abarca sólo un contenido exiguo; por tanto, la mayor parte de lo que llamamos conocimiento conciente tiene que encontrarse en cada caso, y por periodos más prolongados, en un estado de latencia; vale decir: en un estado de inconciencia. (Freud, 2008, pp. 163-164. Énfasis añadido)

Con lo cual nos encontramos por primera vez, con la tesis freudiana de que el conocimiento consciente tiene un origen en un estado latente propio de la estructura de lo inconsciente. Esta es, en últimas, también la tesis que subyace a La formación del espiritu científico, y la razón por la cual Bachelard comprendió la necesidad de postular un psicoanálisis del conocimiento objetivo, pues como podrá notarse toda racionalización, particularmente la que ocurre en la comunidad científica, presupone una mutación que se deriva de la reorganización del inconsciente, y de un trabajo efectivo que hace posible dicha reorganización.

Lo anterior, dicho sea de paso, a propósito de la obra epistemológica, no así, claro está, de la obra estética. La razón de ello la constituye el hecho de 
que se puede asumir o bien la abstracción, o bien la imaginación como vector del propio desarrollo espiritual. Así, al inconsciente, el reino de la fuerza imaginante, de la imaginación dinámica y creadora; a la conciencia el reino de la abstracción, de la razón realizante. Tal abstracción no está dada desde la cuna; implica un proceso milenario de rupturas epistemológicas, tortuoso y feliz, cuya comprensión requiere de las nociones de libido, inconsciente y obstáculo epistemológico.

\section{Noción de obstáculo epistemológico}

Al comienzo del capítulo primero de La formación del espíritu científico, Bachelard afirma categóricamente que "cuando se investigan las condiciones psicológicas del progreso de la ciencia, se llega a la convicción de que hay que plantear el problema del conocimiento científico en términos de obstáculos" (Bachelard, 1985, p. 15). Para comprender el problema del progreso del conocimiento científico en términos de obstáculos epistemológicos, es necesario apartarse de la idea de unas fronteras epistemológicas externas. No se trata, por lo tanto, de predicar acerca de la debilidad del entendimiento humano como factor que no le permitiría dar cuenta de algunos problemas demasiado complejos o ininteligibles; no se trata tampoco de postular un ser trascendente, inmutable, e inaccesible al ya finito espíritu humano, como realidad ininteligible, no importa si ese ser transcendente se postula en el orden de lo material o de lo espiritual, si es que aún puede hablarse de trascendencias materiales. Se trata más bien de comprender, con la noción de obstáculo epistemológico, por lo menos una - pero quizá la más relevante y la más descuidada por las epistemologías clásicas- de las condiciones reales o históricas en las que emerge el espíritu científico y su correlato, el conocimiento científico. Lo anterior en el supuesto de que el espíritu científico no aparece como un dato inmediato, o a priori, sino como un desenvolvimiento que ocurre a partir de diversas rupturas con el espíritu pre-científico o, en este caso, con el espíritu alquimista, cuyo saber, todo, era una proyección del inconsciente en las cosas.
Es en ocasión de una posible explicación de dicha condición de emergencia del espíritu científico que Bachelard afirma:

Es en el acto mismo de conocer, íntimamente, donde aparecen, por una especie de necesidad funcional, los entorpecimientos y las confusiones [...] En efecto, se conoce en contra de un conocimiento anterior, destruyendo conocimientos mal adquiridos o superando aquello que, en el espíritu mismo, obstaculiza la espiritualización. (Bachelard, 1985, p. 15)

En este orden de ideas, conocer en contra de un conocimiento anterior o destruir conocimientos mal adquiridos es lo mismo que superar aquello que en el espíritu obstaculiza la espiritualización. Ahora bien, para otorgar pleno valor epistemológico a la afirmación anterior, es preciso referirse, en primera instancia, a lo que, desde un punto de vista particular, significa en Bachelard la expresión "conocimientos mal adquiridos", para luego mirar en qué sentido es posible plantear que ese tipo de conocimientos obstaculizan la espiritualización, en este caso, la espiritualización del espíritu científico.

En este punto, en la determinación histórica de la noción de saberes mal adquiridos, Bachelard es deudor de una valiosa tradición. En efecto, al igual que Platón en el Teeteto, Bachelard en La formación del espíritu científico diferencia entre aisthesis, doxa y episteme. Tanto para Platón como para Bacherald, la aisthesis es la experiencia básica, la doxa el conocimiento general y la episteme la ciencia. Para Bachelard, la aisthesis y la doxa, como estructuras del conocimiento humano, son conocimientos mal adquiridos. Pero hasta aquí no se ha dicho gran cosa al respecto de esta diferenciación.

Experiencia básica y conocimiento general constituyen los dos obstáculos epistemológicos de los que trata el autor en La formación del espíritu científico. No tendría, pues, nada de especial referirse de nuevo a estos temas, simplemente como saberes mal adquiridos, si no fuera por la particular manera como Bachelard lee la tradición, apoyado en la ya mencionada influencia de los desarrollados teóricos del psicoanálisis y en una lectura particu- 
lar de Platón. Se intentará mostrar, entonces, en lo que sigue, que tanto la aisthesis como la doxa han sido interpretados, en Platón y en Bachelard, como estados estacionarios del espíritu humano, como configuraciones históricas particulares, tensionadas por imágenes proyectadas desde lo inconsciente y no, necesariamente, como malas copias de un objeto externo, realizadas por un sujeto. Lo novedoso de este planteamiento, desde un punto de vista epistemológico, radica, entonces, en el hecho de que con la noción "mal adquirido", Bachelard no se refiere a una mala representación de objetos externos, sino a un momento particular del desarrollo del conocimiento humano que aparece como una proyección del inconsciente y que construye un mundo posible que se objetiva y se revela, como en el caso de los muchos ejemplos de la alquimia, como imágenes o representaciones en las cosas mismas. Al parecer esta tesis epistemológica tiene serias implicaciones no solo para las teorías sobre el conocimiento científico en particular y el conocimiento humano en general, sino también para los procesos de formación.

\section{Los saberes mal adquiridos como estados estacionarios del espíritu humano}

Para una mayor comprensión de este asunto, se divide en este texto el análisis del mismo en cinco puntos, a saber:

\section{La indagación por las condiciones del alma como preámbulo a la emergencia de los discursos sobre los saberes}

Para avanzar, entonces, en el desarrollo de esta tesis que complejiza la noción de obstáculo epistemológico de Bachelard, y la ubica como condición misma del desarrollo del espíritu científico, hay que dar un pequeño rodeo por Platón.

Puede advertirse la manera en que, tanto en el Teeteto como en el Menón, o en el Alcibíades, al examinar lo que sea la ciencia, la virtud o la naturaleza del alma, lo que se pone en juego, en primera instancia, son las condiciones y el devenir del alma en trance o no de concebir. En el Teeteto, por ejemplo, la pregunta que aparentemente abre el diálogo es la pregunta por la ciencia; no obstante, lo que acontece en el fondo de la obra es que Platón examina el alma de Teeteto a lo largo de todo el texto. En efecto, antes de preguntarse por la ciencia Platón se pregunta por las condiciones de quienes han de llevar a cabo el diálogo sobre la ciencia; así la obra se refiere en el fondo a las condiciones de entrada, al proceso en el que se transforman las mismas, y a la condición de salida del sujeto que participa en el diálogo, o lo hace posible. En el texto de Platón, estas condiciones de entrada y de salida presuponen una vigilancia permanente a lo que le acontece a Teeteto durante todo el proceso. Este examen del alma sigue la lógica del reconocimiento crítico de unas condiciones iniciales y la creación de otras necesarias, sin las cuales es impensable la investigación o, lo que es lo mismo, la producción del conocimiento o de la ciencia de algo. ${ }^{4} \mathrm{He}$ aquí pues una primera relación directa entre conocimiento y formación del espíritu: preguntarse por el conocimiento de algo pasa por la pregunta por el sujeto, en cuanto que la emergencia o producción de conocimiento es al mismo tiempo la emergencia del sujeto, pero no como dos entidades separadas, sino como un mismo fenómeno. Es conveniente afirmarlo de entrada: conocimiento y sujeto son la misma cosa.

Al preguntarse por las cualidades del iniciado, Platón centra siempre el tema de las investigaciones filosóficas en la formación. No hay investigación sin el supuesto de un espíritu en devenir. Dicha formación no es otra cosa que el examen que el alma pasa sobre sí misma en función de procurar su transformación en un vector ascendente que va de lo sensible a lo racional. Obsérvese que no se afirma que se vaya de las cosas a los conceptos o de las sensaciones a los juicios, sino del ser sensible al ser racional. Es en ese sentido que Platón pone de presente, en un diálogo sobre la ciencia como lo es el Teeteto, afirmaciones como esta:

4 Para Platón la ciencia de algo no es otra cosa que el examen o diálogo que el alma o pensamiento se dirige a si mimo en un proceso que lo transforma, haciéndolo pasar de la aisthesis a la doxa, y de esta a la episteme. Este diálogo no está libre de incorporar la tradición, que no es más que una manifestación constitutiva del sujeto que dialoga consigo mismo. 
No he visto a ninguno que disfrutase de una naturaleza tan maravillosa. Fácil de aprender, cual ningún otro, y con una dulzura sin igual, posee también un valor con el que aventaja a todos. Tengo para mí que no se ha dado otro ejemplo como él, ni creo que llegue a darse [...] se comporta tan sencilla, tan lisa y eficazmente en sus estudios y muestra tal mansedumbre en sus indagaciones que más semeja el fluir silencioso del aceite. (Teeteto, 142b/144e)

Ahora bien, lo importante aquí, para el análisis que se pretende desarrollar, no es la objetivación de las condiciones mismas del alma (que pueden ser estas $\mathrm{u}$ otras), sino la aceptación, por principio, de que sin la implicación del sujeto no es posible hablar de conocimiento. El origen del conocimiento en Platón es el sujeto. Esto se quiere dejar señalado, porque es relevante para comprender la tradición epistemológica que va de Platón a Bachelard y que, en realidad nada tiene que ver con un idealismo ingenuo en términos de la existencia a priori del sujeto o de la existencia de esencias trascendentales e inmutables. No en Platón, mucho menos en Bachelard.

\section{La crítica de Platón al sujeto sin sujeto}

En efecto, tiene que decirse de paso, que en toda su obra, incluidos el Teeteto y el Banquete, pero de manera brillante en la trilogía: la Apología de Sócrates, el Critón y el Fedón, Platón se ha ocupado de mostrar los diferentes matices del ser racional. En el Sócrates platónico, en la diversidad con la que es presentado en la obra platónica este personaje, se encuentra diseminada una polisemia sobre el ser racional. Sócrates aparece siendo racional de diversas maneras. No obstante, la estructura lógica del diálogo que por excelencia promueve el Sócrates platónico obedece a los principios de necesidad y razón. En la trilogía mencionada, la obsesión por la pura estructura lógica del discurso, por la argumentación per se, en consecuencia con estos dos principios, desemboca en una filosofía que prepara para la muerte, pues, según el Sócrates del Fedón, "cuantos se dedican por ventura a la filosofía en el recto sentido de la palabra no practican otra cosa que el morir y el estar muertos" (63 b). El postulado según el cual "es la mente lo que pone todo en orden y la causa de toda las cosas" (Fedón, 96d), que se opone hábil y razonablemente al principio material (aire, agua, fuego, tierra, átomo, protón, fotón, partícula elemental) propio de la investigación natural de la naturaleza, deviene - al extrañarse de su principio fundante-, una filosofía como preparación para la muerte. La reducción del pensamiento, y del diálogo del pensamiento consigo mismo, a los principios de necesidad y razón desembocan en un renunciamiento a la vida, no cabe duda que lleno de valor, de dignidad, lógicamente consecuente y necesario, pero al fin de cuentas en una renuncia a la vida.

Esta imagen de renuncia a la vida, al horizonte de la historia vital de lo cotidiano en favor del argumento lógico y del principio de necesidad, aparece magistralmente representado también en el último movimiento del Banquete cuando Alcibíades revela una terrible verdad respecto del Sócrates al cual Platón critica su fría virtud. En efecto, ese Sócrates no solo ha practicado una filosofía como preparación para la muerte, sino que ha ocultado en su tenaz capacidad para argumentar una profunda incapacidad para amar. Esto lo afirma Alcibíades en el Banquete cuando dice:

Sin embargo, no soy yo el único con el que se ha portado así, sino que hizo también lo mismo con Cármides, Glaucón, Eutidemo, hijo de Diocles, y con muchísimos otros, a quienes engañando este como si fuera su amante, en vez de amante resulta más bien amado. (222c)

Por otra parte, este relato de Alcibíades es cerrado dramáticamente, de tal manera que al finalizar el diálogo entra a casa de Agatón un inmenso tropel de juerguistas y todos los asistentes al banquete se ven obligados a beber una enorme cantidad de vino sin orden alguno, contexto en el cual Aristodemo narra:

Al despertarse vio que los demás estaban durmiendo o se habían ido, y que tan sólo Agatón, Aristófanes y Sócrates estaban todavía despiertos y bebían de una gran copa que se pasaban de izquierda a derecha [...] mientras eran obligados a admitir (algo) sin seguirle demasiado bien, daban 
cabezadas de sueño hasta que se durmieron, primero Aristófanes y luego Agatón, cuando ya era de día. Sócrates, entonces, después que los hubo dormido, se levantó y se fue [...] una vez que llegó al liceo, se lavó y pasó el resto del día como en otra ocasión cualquiera. (Banquete, 323d)

Esta imagen del sujeto vaciado del interés por la vida, a fuerza de una especie de represión de la fuerza generatriz instalada por el seguimiento a ultranza de los principios de necesidad y razón, constituye siempre una antesala en las obras de Platón para mostrar la otra cara de un sujeto instalado sobre la fuerza pulsional vital que desprende desde sí el deseo de conocer. No es, pues, al sujeto instituido en la pura operación lógica, o al pensamiento puro absorto en sí mismo y sordo a las voces de los dioses, al que Platón instala como principio ordenador, pues, es evidente su crítica permanente a ese estado del alma, sino a lo que puede llamarse una función de organización emergente propia de la dinámica pulsional, la cual permite explicar el todo y las partes, así como las múltiples relaciones recursivas y posibles entre estos dos aspectos. Divorciado, escindido del principio vital, de la fuerza o plasma germinal (Freud, 2008, p. 76) el pensamiento es puro juego lógico, un vacío, una negación de la vida; desprendido del principio ordenador, del pensamiento, la fuerza generatriz es puro devenir puro cambio. En la relación Eros-Psique radica la posibilidad de un nuevo orden creador exuberante y con sentido, por lo menos con sentido humano.

\section{La dinámica Eros-Psique y el problema de la eternidad del sujeto en el proceso de generación y parto}

Este segundo sujeto, en esta tradición que aquí se señala, tiene una particularidad que es la que interesa resaltar en este escrito; en efecto, se trata de un sujeto complejo que se debate en la tensión entre lo consciente y lo inconsciente y que tiene en ambos autores un claro vector de desarrollo racional, pero que, así mismo, encuentra su primer principio en una fuerza pulsional llamada libido o, quizá en términos más generales, en un inconsciente constituido por arquetipos. El sujeto platónico y el sujeto bachelardiano son un sujeto histórico escindido que ha perdido su unidad fundamental eros/psiquis, que sufre esta tensión de manera primordial y que busca restituir la unidad perdida en el deseo de saber.

Entonces, reconocida y satisfecha esa primera condición o, lo que es lo mismo, definida y dada por sentada la disposición de un alma - cuyas características quedan mencionadas-, en seguida Teeteto es interrogado por un tal Sócrates. Ahora bien, dicho diálogo entre Teeteto y Sócrates se produce previo retrato hablado, llevado a cabo por Teodoro, según el cual Teeteto se asemeja a Sócrates mismo. En este caso, da la impresión de que se va a desarrollar un diálogo de Sócrates consigo mismo; esto es: del alma consigo misma. Principio que aparece en muchos pasajes de la obra de Platón y al que se hará referencia más adelante.

No obstante, este diálogo tiene una condición adicional que consiste en que se puede dar solo si la divinidad lo permite. Así, el diálogo SócratesTeeteto se despliega en el marco del supuesto según el cual Teeteto es interrogado por un alma cuyo dios o daimon la arroja a preguntar y a buscar la generación y el parto en la belleza. En desarrollo de las dos ideas expuestas en este párrafo: el diálogo del alma consigo misma y la intervención de la divinidad como apertura del mismo, conviene ver el siguiente pasaje:

No has oído decir que soy hijo de una comadrona? [...] ¿Y te has informado también que yo ejerzo ese mismo arte? [...] mi arte mayéutica tiene seguramente el mismo alcance que el de aquellas, aunque con una diferencia y es que se practica con los hombres y no con las mujeres, tendiendo además a provocar el parto en las almas y no en los cuerpos [...] la divinidad me obliga a este menester con mi prójimo [...] Los que se acercan a mí semejan de primera intensión que son unos completos ignorantes [se encuentran en estado de llenura], aunque luego todos ellos, una vez que nuestro trato es más asiduo, y que por consiguiente la divinidad les es más favorable, progresan con maravillosa facilidad [quedan en estado concebir o ya no creen saber lo que no saben] [...] ¡A la causa de tal engendro somos la divinidad y yo. (Teeteto, 149b/150d. Énfasis añadido) 
Así, el alma que dialoga consigo misma (SócratesTeeteto) en calidad de comadrón, está arrebatada por un daimon, una divinidad, una fuerza generatriz. Este es un dato que es reiterativo en varios diálogos. En el Alcibíades, por ejemplo, Sócrates afirma: "Es un dios, Alcibíades, el que no me permitía hasta hoy dialogar contigo. La confianza que tengo en él me hace decir que no se revelará a ti por ningún otro que no sea por mí" (Alcibíades, 125b).

Para Platón, la divinidad o daimon interior, se sabe por el Banquete, es Eros, amante de lo eterno. El amor (Rhome, fuerza generatriz) en Platón aparece como solicitud e intenso deseo de generación y parto; estas últimas como condición necesaria y única posible de mantener la inmortalidad o lo que es lo mismo de la permanencia en el cambio. Ahora bien, como se sabe, para Freud ese daimon al que se refiere Platón de manera constante es una pulsión, una fuerza psíquica interna que se diferencia del instinto (Freud, 2008, p. 116) y de la cual se despliegan, entre otros, el yo y el mundo de los objetos (Freud, 2008, p. 74). Así, pues, esta alma que dialoga consigo misma tiene un principio dinámico oculto que la determina, el cual busca lo eterno de si en al acto de procreación. El destino de tal fuerza generatriz consiste en garantizar el movimiento exuberante de la creación. Por tanto, no es su objeto, su destinación, la belleza en sí misma, sino la generación y el parto en la belleza. Así, afirma Platón, el objeto del amor es:

La procreación en la belleza tanto según al alma como según el cuerpo [...] La unión de varón y de mujer es procreación y es una cosa divina pues la preñez y la generación son algo inmortal [...] El amor es amor de la generación y del parto en la belleza. ¿Por qué es la generación? Porque es la generación algo eterno e inmortal [...] Necesariamente, el amor será amor de la inmortalidad [...] La naturaleza mortal busca en lo posible existir siempre y ser inmortal. Y solamente puede conseguirlo con la procreación, porque siempre deja un ser nuevo en lugar del viejo [...] No te admires pues, si todo Ser estima por naturaleza a lo que es retoño de sí mismo, porque es la inmortalidad la razón de que a todo ser acompañe esa solicitud y ese amor". (Banquete, 205e/206a/207e. Énfasis

añadido)

Queda claro, entonces, que al alma, al pensamiento detrás del cual camina Platón, va unida una figura divina, una voz interior, oculta, que murmura solo en sueños, y de la cual parece brotar el principio de su propia dinámica: la búsqueda de la inmortalidad en la acción de generación y parto. Lo Uno inmortal no lo es, a priori, por su condición de identidad consigo mismo en la forma o en la esencia, sino por la dinámica pulsional primigenia cuyo destino es la creación que constituye estados estacionarios diversos de los que la esencia y la forma son sus maneras de aparecer. Este es pues el sujeto que Platón pone a examinarse a sí mismo con el fin de indagar acerca de qué sea la ciencia.

\section{La aisthesis y la doxa dos casos de estados estacionarios del espíritu}

El sujeto al que se viene haciendo referencia en este escrito, al examinarse a sí mismo, en el proceso de generación y parto, toma conciencia de sí y, por decirlo de esta manera, en este acto de emergencia de la conciencia pasa por diferentes estados estacionarios tales como la aisthesis y la doxa. De este modo, la ciencia como sensación y la ciencia como opinión, antes que estructuras formales, trascendentales y objetivadas, son ante todo dos estados de comprensión constitutivos de la estructura de la subjetividad.

Conviene, entonces, caracterizar el lugar que ocupan tanto la aisthesis como la doxa en la tradición a la que se está haciendo referencia con el fin de mostrar al espíritu científico, en esta tradición, como un proceso de espiritualización trabado en sus propios estados estacionarios. Ese lugar está marcado tanto en Platón como en Bachelard, por dos estados del alma o del espíritu que detienen el proceso de generación y parto, y no como un error de correspondencia entre la cosa y la idea.

La primera gran parte del Teeteto es dedicada, efectivamente, a plantear la relación entre la aisthesis, o teoría de la ciencia como sensación, y el devenir, planteado por Heráclito. Así, el principio 
histórico que sirve de base tanto al planteamiento como a la crítica de la aisthesis como ciencia es el del devenir como el principio de todas las cosas. En este punto Platón, a partir de varios desarrollos tanto de orden retórico como argumentativo, concluye que el mundo de la sensación es heteróclito y en extremo relativo y que en esa relatividad no puede consistir la ciencia. Dado su carácter efímero y extremadamente relativo, las sensaciones como expresión inmediata del devenir en el hombre, del movimiento como eterno acontecer en las cosas humanas, no son garantes de eternidad para la fuerza pulsional que emerge como conciencia en el hombre. No otra parece ser la razón de fondo por la cual Platón busca establecer el principio de la ciencia en otro lugar. En efecto, la primera parte del diálogo finaliza de la siguiente manera:

Sócrates: Ya no podrá decirse, Teeteto que sensación y ciencia sean una misma cosa.

Teeteto: No parece que sea así, Sócrates. Y ahora queda suficientemente probado que la ciencia es algo diferente a la sensación.

Sócrates: [...] Con todo hemos dado un buen avance al no tener que buscarla enteramente en la sensación sino en ese acto, cualquiera que sea, por medio del cual se aplica el alma por si misma a la consideración de los seres. (Teeteto, 187b. Énfasis añadido)

Así, pues creer que se sabe lo que no se sabe, en este caso que la ciencia y la sensación son la misma cosa, es el estado estacionario inicial del sujeto Sócrates-Teeteto, el cual es transformado en un movimiento dialógico, nombrado por la tradición como arte mayéutica, hasta llegar a concebir en sí mismo una situación nueva. Lo anterior se hace más evidente si se tiene en cuenta que Sócrates, en el desarrollo del último argumento de esta primera parte del diálogo, le dice a Teodoro, refiriéndose a Teeteto, lo siguiente: "Conviene [...] que, antes bien, tratemos de liberarle con nuestra arte mayéutica de la concepción sobre la ciencia que lleva dentro" (184d).
Se trata, pues, de un trabajo sobre el sujeto y no sobre las cosas. La segunda gran parte del Teeteto, Platón la dedica a examinar la tesis según la cual la ciencia es la opinión verdadera y no la falsa, por supuesto. La mayor parte de este estudio lo desarrolla, también, tomando como referente el principio de Heráclito. No desconoce el principio de la inmovilidad del ser, de la escuela de Parménides, pero no lo desarrolla suficientemente en este texto. También en este asunto, Platón, a partir de la aplicación de los tres principios de la lógica formal, como reguladores del diálogo, determina que la ciencia no puede ser la opinión verdadera, ni la opinión verdadera acompañada de razón. En este punto, es al comienzo que Platón refiere la idea según la cual la opinión (doxa) es un estado estacionario del alma en trance de conocer y no un saber dado:

Sócrates. Una cosa me conturba todavía, que ya me llenó de preocupación en otras ocasiones: me veo en la gran dificultad de no saber decir respecto de mí mismo y respecto de otro en que consiste ese estado del alma que nos afecta y de qué modo se produce [...] Me refiero concretamente a la opinión falsa. (Teeteto, 187b. Énfasis añadido)

Así, pues, la opinión, en este caso la opinión falsa, que no constituye ciencia - como tampoco la opinión verdura acompañada de razón-, es un estado del alma que nos afecta y no un ente trascendente o idea correspondiente con una realidad cualquiera externa.

No es ni en las sanciones ni en las opiniones en donde reside el lugar de la generación y el parto. Tanto la aisthesis como la doxa se presentan como estados del alma que detienen la promoción del ser pensante, el cual requiere de una dinámica pulsional rectificada para dinamizarse. Esto es lo que nos lega Platón como tesis central de su epistemología o conocimiento del conocimiento. De ahí que los dos estados del alma a superar, las primeras quimeras a abortar, sean la disposición del alma hacia las sensaciones y la disposición del alma hacia la opinión. Entonces, no es porque la aisthesis y la doxa sean falsas por su inadecuada correspondencia con alguna esencia material o abstracta, por lo que 
deben ser superadas, sino porque en ellas el alma se extravía de su objetivo inicial: servir a amor de cuna para buscarse la eternidad en el proceso de generación y parto.

Nótese que no se está afirmando que el conocimiento común y la opinión sean conocimientos que deban ser superados, sino los estados del espíritu, que es en lo que en últimas enfatiza Platón. Razón por la cual termina el diálogo de la siguiente manera:

¿Estamos entonces, querido, en trance de parto y ya de dar a luz con respecto a la ciencia, o, por el contrario, nos encontramos libres de todo ello? [...] Si después de todo lo que queda dicho, Teeteto, tratas de concebir o concibes realmente algo mejor no cabe duda de que habrás alcanzado la plenitud de la ciencia, a través de este examen. Pero si, en cambio, permaneces vacío de todo, entonces serás menos pesado para los que frecuentan tu trato, e incluso más humano, porque ya no pensarás que sabes lo que realmente no sabes. Ese es el poder de mi arte. (Teeteto, 210d)

En este caso, como se había advertido, un conocimiento mal adquirido es, entonces, un estado del alma que hay que superar. Alcanzar la plenitud de la ciencia es concebir algo mejor y no creer que se sabe lo que no se sabe. Creer que se sabe lo que no se sabe es un estado de llenura que obstaculiza el saber. Alcanzar la plenitud de la ciencia es un movimiento creador que se mide por la transformación de uno mismo en el diálogo. Dicha transformación pasa por el asombro, por el reconocimiento del no saber, es decir, por la rectificación del estado de llenura. No se trata, por lo tanto, ni de principios generales, ni de métodos precisos que haya que aplicar para acceder al orden de las cosas, sino de la reorganización del sujeto a partir un diálogo que lo humaniza.

Esto es lo que toma Bachelard de la tradición platónica para plantear la noción de obstáculo epistemológico como un estado del espíritu científico y no como un error conceptual externo. En efecto, se sabe, por la estructura del libro La formación del espíritu científico, que el pensamiento empírico al que se hace referencia es la aisthesis. En Bachelard, dicho pensamiento se presenta como la suma de los obstáculos animista, sustancialista y verbal, entre otros, cuya condición heteróclita se queda en el puro perecer sin alcanzar el estado de generación. Por otra parte, el segundo sistema es la doxa u opinión, cuya estructura de acuerdo con Bachelard, consiste en generalizaciones que inmovilizan el pensamiento, que es otra forma del perecer. Es en este contexto que afirma Bachelard:

Veremos así el espíritu científico trabado desde su nacimiento por dos obstáculos, en cierto sentido opuestos. Tendremos, pues, la ocasión de captar el pensamiento empírico en una oscilación llena de sacudidas y de tirones, y finalmente, todo desarticulado. Más esta desarticulación torna posible movimientos útiles. De manera que el epistemólogo mismo es juguete de valorizaciones contrarias que se resumirían bastante bien en las siguientes objeciones: es necesario que el pensamiento abandone al empirismo inmediato. El pensamiento empírico adopta, entonces, un sistema. Pero el primer sistema es falso. Es falso pero tiene por lo menos la utilidad de desprender el pensamiento alejándolo del conocimiento sensible. (Bachelard, 1985, p. 23)

Ahora bien, para avanzar en la determinación de la noción de obstáculo epistemológico se hace necesario advertir que estos dos estados del espíritu, a los que precisamente se les ha reconocido la condición de obstáculos epistemológicos, aparecen en Bachelard como tipos de investidura de la libido sobre la conciencia. ${ }^{5}$ Tanto el pensamiento empírico, como la generalización consisten, en últimas, en proyecciones del inconsciente sobre los objetos, como se verá en seguida. A mi juicio, tanto la adopción como el desprendimiento del pensamiento a los que se refiere Bachelard en este punto son una función derivada de la investidura de la pulsión sobre sí misma que da origen a diversas dinámicas y formas del pensamiento.

5 Quizá debamos recordar que este tipo de investidura supone para el psicoanálisis creación de aquello de lo que se dice ha sido investido. Así, por ejemplo, la investidura de objeto supone la creación del objeto como objeto de deseo. Por otra parte, la investidura yoica supone la creación del yo (Cf. Freud en introducción al narcisismo). 


\section{Necesidad funcional de los entorpecimientos y las confusiones}

Aquello que Bachelard anuncia como necesidad funcional de la emergencia de los entorpecimientos y las confusiones, al definir la noción de obstáculo epistemológico, alude, en primera instancia, a la comprensión de una cierta relación dialógica primigenia que se origina en la investidura de la fuerza pulsional sobre sí misma. En segunda instancia, apunta al reconocimiento o bien de que la conciencia emerge históricamente como un desprendimiento del inconsciente o de que el yo aparece como consecuencia de la investidura de la libido. Si esto es así, dicha investidura crea tanto el mundo de los objetos como a la conciencia; pues, investir al yo o investir al objeto presupone en la teoría psicoanalítica la creación de dicho yo y de dicho objeto. Basado en razones de este tipo: la proyección del inconsciente vivida como cualidad de la materia, y la necesidad histórica del desarrollo que llevó a la conciencia a diferenciarse del inconsciente, Bachelard afirma finalmente:

Es en los detalles de la investigación objetiva donde debemos hacer sentir las resistencias de los obstáculos epistemológicos. Es ahí donde veremos la influencia del libido, libido tanto más insidioso cuanto más rápidamente ha sido apartado y cuya represión es, en las tareas científicas más fácil y más necesaria a la vez. (1895, p. 216. Énfasis añadido)

El reconocimiento y la insistencia en la influencia del libido en la investigación objetiva es el aspecto que merece mayor atención y que debe ser subrayado como aporte fundamental en el pensamiento bachelardiano: libido tanto más insidiosa cuanto más ha sido reprimida. En este punto, no cabe duda, Bachelard es claramente deudor de una cierta tradición, incluso opuesta, del pensamiento psicoanalítico: Jung-Freud. En apoyo a esta tesis bastará con señalar dos planteamientos de Jung que subyacen a los análisis de Bachelard sobre la noción de obstáculo epistemológico:
Primero:

La oposición de la conciencia respecto del inconsciente, así como la subestimación de este último, responde a una necesidad histórica de desarrollo, pues de no ser así la consciencia nunca habría podido diferenciarse del inconsciente. (Jung, 2011, p. 70. Énfasis añadido)

Segundo:

El Alquimista vivía su proyección como cualidad de la materia. Y lo que en realidad vivía era su propio inconsciente. $\mathrm{Y}$ así el alquimista repetía la historia del conocimiento de la naturaleza en general. Como es sabido, la ciencia comenzó con los astros, en los cuales la humanidad descubrió sus dominantes del inconsciente [...] Tales proyecciones se repiten siempre cuando el hombre procura explorar una oscuridad vacía que él llena involuntariamente con figuras vivas. (Jung, 2011, p. 269. Énfasis añadido)

Así, siguiendo las huellas de estos dos supuestos, la insidiosa influencia del libido en la investigación objetiva obedece a la relación primigenia entre libido y conciencia o libido y razón. La aparición de los entorpecimientos y las confusiones en el progreso y comprensión del devenir del espíritu científico, se explican, entonces, como funcionalmente necesarios en el marco de una teoría que reconoce la proyección del inconsciente en las cosas y la diferenciación de la conciencia como emanada del inconsciente, como supuestos teóricos y prácticos de la génesis del conocer. En ese contexto, lo funcional en Bachelard alude, entonces, al reconocimiento del hecho de que sin el desgarramiento de la conciencia respecto del inconsciente no habría surgido conciencia; es decir, la conciencia se debe de alguna manera al inconsciente, razón por la cual no se puede partir, para el caso concreto de la comprensión del desarrollo de espíritu científico, de un lugar que desconozca las determinantes del inconsciente sobre la conciencia. De aquí la importancia de un psicoanálisis del conocimiento objetivo.

Ahora bien, resta quizá señalar cómo la relación de proyección entre el inconsciente y los objetos, creados por dicha proyección, se manifiesta de 
forma distinta en el espíritu precientífico y el científico. Esta diferencia, debe ser claro ya, no obedece a un cambio de origen, pues este sigue siendo el mismo, sino a una dinámica diferente donde el estado de conciencia emergente está orientado por el principio de organización y por un claro vector de abstracción. En esta condición Bachelard va a promover un cambio que va desde la proyección directa del inconsciente a las cosas, hacia la realización de tales cosas mediada por la vigilancia intelectual de las comunidades académicas. Podría afirmarse, en este sentido, que el psicoanálisis del conocimiento objetivo propuesto por Bachelard consiste en un proyecto histórico que trabaja en la línea de la sublimación, en función del aprovechamiento de las fuerzas psíquicas pulsionales aplicadas al acto de creación de nuevas realidades posibles. Este aspecto puede ser seguido, en parte, en la noción de ruptura epistemológica a la que se hará alguna alusión en este momento.

\section{La noción de ruptura epistemológica}

En primer lugar, y para ser radicales, una ruptura epistemológica es una mutación del espíritu. Estas mutaciones solo pueden entenderse en función del vector de organización que presupone la emergencia de la racionalidad. Únicamente se puede hablar de ruptura epistemológica en función de una reorganización particular del saber que es, al mismo tiempo y en el mismo sentido, una reorganización del espíritu.

\section{Ruptura epistemológica y realización}

Para Bachelard, la reorganización es un nuevo orden en los ámbitos de la teoría y de la experiencia que se revela en una nueva forma de ser del espíritu humano en dominios específicos. Hay que alejarse, pues, de la tentación de creer que la dirección de la ruptura va de la superación del inconsciente a las cosas mismas, si con esta última noción nombramos alguna cosa en sí, o algún ente objetivo del que se pueda predicar algo como independiente del hombre. Es decir, si bien, por definición y por principio, toda ciencia tiene su origen primero en la proyección del inconsciente (arquetipos o pulsiones) sobre el mundo, o lo que sería más exacto: en la creación de un mundo manifiesto, desde el inconsciente que se proyecta en imágenes que son objetivadas como lo real; si bien esto es cierto, de acuerdo con los presupuestos tomados del psicoanálisis, la ruptura con este estado de cosas, o proyección, no presupone la superación absoluta de la mediación del inconsciente para recuperar por arte de algún otro artilugio (razón, entendimiento o voluntad trascendentales) las cosas mismas en su esencialidad. Ni siquiera, es conveniente creerlo, se podría pensar en la superación del inconsciente, en términos absolutos.

Muy por el contrario, quizá lo que haya que reconocer es que en función de la fuerza generatriz reconocida como constitutiva de lo humano, el hombre ha devenido históricamente en una especie de demiurgo, ${ }^{6}$ orientado por la misma fuerza pulsional primigenia que explica la exuberancia de la primavera. De los muchos mundos posibles, los construidos por las diferentes ciencias son tan solo unos, pero para quien está en una comunidad científica particular es $s u$ mundo posible. Para Bachelard, pues, la superación de un obstáculo, es decir, una ruptura epistemológica propiamente dicha es un acontecimiento histórico (tanto en lo individual como en lo colectivo) que da cuenta del nacimiento o variación de la razón en el hombre, como una fuerza cuya función ascendente es la de la organización de lo real como algo nuevo y distinto -incluso a la naturaleza - y en ese sentido como creación o, más exactamente, como realización.

Así, de la proyección del inconsciente a las cosas, que podría ser comprendido como una acción de realización de esas cosas mismas en un lugar cultural e histórico determinado, se ha pasado a una proyección de la función de organización del inconsciente, a otras cosas mismas, en otro lugar histórico y cul-

6 El demiurgo (en griego: $\Delta \eta \mu 10 v \rho \gamma o ́ s$, Dèmiurgos), en la filosofía gnóstica, es la entidad que sin ser necesariamente creadora es impulsora del universo. También es considerado un semidiós creador del mundo y autor del universo en la filosofía idealista de Platón y en la mística de los neoplatónicos.

Por tanto, demiurgo significa literalmente: maestro, supremo artesano, hacedor; aunque resaltando el griego signific aría creador. (Tomado de: http://es.wikipedia.org/wiki/Demiurgo) 
tural específico; es decir, a la realización de otros mundos, abstractos y materiales, posibles.

La ruptura epistemológica como proceso de reorganización del espíritu no anula el inconsciente, por el contrario, este último ha dado origen a una nueva función que produce otro tipo de mundos y otro tipo de cosas como condición del nuevo estado de proyección que garantiza, por ahora, la inmortalidad tanto de la libido como de su función de organización, es decir, de la razón. Los conceptos de reorganización, organización y realización son fundamentales en la obra de Bachelard. ${ }^{7}$

Quizá la siguiente cita de Kuhn ayude a ilustrar un poco este hecho; el de la reorganización, como un fenómeno que ocurre en el espíritu científico rodeado de unas condiciones particulares:

Estaba sentado a mi mesa con el texto de la Física de Aristóteles delante de mí y un bolígrafo de cuatro colores en la mano. Levantando los ojos miré abstraídamente por la ventana de mi habitación y aún retengo la imagen visual. Súbitamente los fragmentos de mi cabeza se ordenaron por si mismos de un modo nuevo encajando todos a la vez. Se me abrió la boca, porque de pronto Aristóteles me pareció un físico realmente bueno, aunque de un tipo que yo nunca hubiera creído posible. Ahora podía comprender por qué había dicho lo que había dicho..." (Kuhn, 1996, p. 63)

Para no conducir a equívocos hay que enfatizar que Kuhn era un estudiante graduado de física que se encontraba trabajando en la preparación de un curso sobre el desarrollo de la mecánica y que precisamente estaba estudiando a Aristóteles para esos fines. Es decir, que no es un espectador solitario, arrebatado por las imágenes a través de la ventana,

7 Esta es otra deuda de Bachelard con la tradición platónica, en la cual los dioses castigaron al hombre por haber descubierto el principio de la inmortalidad en el cambio y la renovación; esto es, en la procreación. A este respecto, no solo el mito de Adán y Eva sino múltiples mitos recreados por Platón parecen apuntar a este principio vital en la emergencia del conocimiento. La piedra filosofal platónica, a mi juicio, radica en este punto: el amor a la generación y al parto en la belleza como camino a la inmortalidad del alma. La manera de permanecer de lo que eternamente muere, de lo que cambia, como el alma misma, está en el rejuvenecerse constante a partir de la creación que no es otra cosa que el arquetipo del ave fénix. sino ocupado de sus pensamientos en referencia a una escuela en particular. Es precisamente ese pensador de un ámbito particular de la experiencia o, más exactamente, de una comunidad científica particular, ocupado de sus pensamientos, el que ve como se reorganiza ante él y en él, de manera novedosa las partes en una nueva unidad. La aclaración es importante, antes que por Kuhn, por Bachelard, para quien ese tipo de fenómenos son el resultado del trabajo efectivo y no de la iluminatio, contra la que precisamente construye su obra epistemológica y no así su obra estética.

Esa novedad de espíritu, es decir, esta ruptura epistemológica, lejos de provenir de una intuición, lejos de ser una proyección directa del inconsciente, es el resultado de un trabajo efectivo que se desarrolla no tanto en la soledad de una habitación como sí en el diálogo que se lleva a cabo en la escuela. Bachelard, afirma al respecto que la falsa ciencia carecía de varios aspectos necesarios para la maduración de la razón, tales como constituir al sujeto en principios de necesidad, esto es, constituir al sujeto en racionalidad; eliminar la contingencia de saber, asistir y someterse al control de la escuela oficial; trabajar por el carácter orgánico de la obra; comprometerse con el trabajo del laboratorio y, lo más revelador de su planteamiento: el hecho de que en ella el espíritu científico es guiado por un interés en trance de abstraer y quintaesenciar. ${ }^{8}$

Para Bachelard, "una tesis como la nuestra, [...] plantea el conocimiento como una evolución del espíritu, [...] acepta variaciones respecto a la unidad y perennidad del yo pienso [...]" (1984, p. 12. Énfasis añadido). De esta manera, para Bachelard, "tener acceso a la ciencia es rejuvenecer espiritualmente, es aceptar una mutación brusca que ha de contradecir a un pasado" (Bachelard, 1985, p. 16. Énfasis añadido). Esta filosofía que postula el conocimiento como evolución del espíritu, como reorganización de la razón y como realización de mundos posibles no solo contradice las filosofías tradicionales que postulan la unidad, la trascendencia y la a-historicidad de la razón, sino que concibe toda mutación del

8 Otra vez la influencia platónica. 
conocimiento-espíritu como un rejuvenecimiento. Esta formulación lejos de ser una bella metáfora constituye un principio epistemológico inalienable.

Si el espíritu científico - una especie de consciencia histórica emergente que reconoce la otredad, no como las cosas en sí mismas sino como su principio fundante- aparece como un desprendimiento de las bases primitivas (arquetipos o fuerzas pulsionales) que constituyen el inconsciente es porque dichas bases son lo primigenio, lo fundante que muta en algo nuevo, emergente: la razón. A este principio fundante y constituyente debe la razón dinámica el principio de su movilidad. Esa dinámica pulsional es la que le da a la razón motivos de movilidad. Es en este sentido que Bachelard, a propósito de su obra dedicada a la estética, afirma:

No ha faltado quien se asombre de que un filósofo racionalista preste tanta atención a ilusiones y a errores, y que necesite sin cesar representar los valores racionales y las imagines claras como rectificaciones de datos falsos. En los hechos, no le vemos ninguna solidez a un racionalismo natural, inmediato, elemental. No es posible instalarse de golpe en el conocimiento racional; ni se logra de primera una perspectiva justa de las imágenes fundamentales. ¿Racionalista? Tratamos de llegar a serlo, no sólo en el conjunto de nuestra cultura, sino en lo pormenorizado de nuestros pensamientos, en el orden detallado de nuestras imágenes familiares. (Bachelard, 1978a, p. 16)

El asombro de quienes así se expresan, en este caso, puede entenderse porque "se cree en una razón constituida antes de todo esfuerzo de racionalidad" (Bachelard, 1978b, p. 16). No obstante, para Bachelard es claro que la razón, lejos de ser el primer principio, el Órganon, a priori, es una conquista, un trabajo. Es precisamente el trabajo polémico, la condición dialógica, la que caracteriza a la razón emergente, como razón polémica; lo que da a la razón la condición de ser función de organización y reorganización. El estatuto fundante, el que explica la diferenciación de la razón, respecto del inconsciente colectivo es, entonces, el diálogo, la polémica como dinámica de lo racional.
Ahora bien, para efectos de la aplicación de estas reflexiones a la comprensión de lo que podría ocurrir en un programa de formación de docentes o de formación de investigadores en educación, podemos preguntarnos: ${ }_{i}$ Es posible provocar una ruptura epistemológica, o estas ocurren de manera espontánea, es decir sólo se pueden verificar históricamente? Sin pretender agotar esta indagación podemos decir que tanto la noción de filosofía dialogada como la noción de perfil epistemológico aplicadas a categorías particulares constituyen alternativas que Bachelard propone como caminos posibles para procurar dichas rupturas. Las nociones de razón polémica y filosofía dialogada cobran aquí un valor especial. El acto fundacional del pensar, que para Bachelard no se diferencia del razonar, es la polémica, el diálogo que el sujeto, en principio libidinal, inconsciente, tiene consigo mismo y del que se desprende dicho pensar. Es la polémica, el diálogo, el principio que explica el extrañamiento de la estructura arquetípica primigenia sobre sí misma y que da origen a la conciencia, al pensar, al razonar. Sin esta polémica, sin este diálogo constitutivo no es pensable el devenir de dicha consciencia. Por eso, reconocer obstáculos epistemológicos y provocar rupturas es la tarea del epistemólogo comprometido. Este tiene en su haber histórico la filosofía dialogada y la construcción de perfiles epistemológicos como vías de posibilidad.

\section{Referencias}

Bachelard, G. (1978a). El racionalismo aplicado. Buenos Aires: Paidós.

Bachelard, G. (1978b). El agua y los sueños. México: Fondo de Cultura Económica.

Bachelard, G. (1979). El materialismo racional. Buenos Aires: Paidós.

Bachelard, G. (1984). La filosofía del no. Buenos Aires: Amorrortu.

Bachelard, G. (1985). La formación del espíritu científico. México: Siglo XXI.

Bachelard, G. (1988). El compromiso racionalista. México: Siglo XXI.

Freud, S. (2008). Obras completas: Contribución a la historia del movimiento psicoanalítico: Trabajos sobre 
metapsicología y otras obras: 1914-1916. Buenos Aires: Amorrortu.

Heisenberg, W. (1976). La imagen de la naturaleza en la física actual. Barcelona: Seix Barral.

Jung, C. G. (1982). Psicología y simbólica del arquetipo. Barcelona: Paidós.

Jung, C. G. (2011). Psicología y alquimia. Bogotá: Editorial Solar.

Kuhn, T. S. (1996). ¿Qué son las revoluciones científicas? y otros ensayos. Barcelona: Paidós.

Platón. Obras Completas. Madrid: Aguilar. Segunda edición, novena reimpresión. 